\title{
Assessment of Knowledge and Practices of Prostate Cancer Screening Among Men in the Lower Manya Krobo Municipality in the Eastern Region of Ghana
}

\author{
Victoria Nartey Laweh ${ }^{1,2}$, Stephen Manortey ${ }^{1, *}$ \\ ${ }^{1}$ Ensign College of Public Health, Kpong, Ghana \\ ${ }^{2}$ Greater Accra Regional Hospital, Accra, Ghana
}

Email address:

steve.manortey@ensign.edu.gh (S. Manortey)

${ }^{*}$ Corresponding author

To cite this article:

Victoria Nartey Laweh, Stephen Manortey. Assessment of Knowledge and Practices of Prostate Cancer Screening Among Men in the Lower Manya Krobo Municipality in the Eastern Region of Ghana. Cancer Research Journal. Vol. 9, No. 1, 2021, pp. 41-52.

doi: $10.11648 /$ j.crj.20210901.16

Received: February 6, 2021; Accepted: February 16, 2021; Published: February 23, 2021

\begin{abstract}
Prostate cancer is the leading cause of cancer-related deaths among men 40 years and above globally. Incidence and mortality rates are higher in African men as they grow older. Prostate cancer is amenable to early detection by screening which can prevent and reduce cancer deaths. Unfortunately, it is often detected late in the Ghanaian population due to lack of voluntary screening. This study assessed the knowledge and practices of prostate cancer screening uptake among men in the Lower Manya Krobo Municipality (LMKM) in the Eastern Region of Ghana. The study employed a cross-sectional design that used quantitative methods (structured questionnaire) to collect data from 363 respondents using a multistage sampling technique. Chi-square test statistics were used to estimate the association between the knowledge, practices and perception (dependent variables) and socio-demographic characteristics (independent variable) of respondents. Multiple binary logistic regression model was used to measure the strength of association between the variables at a $95 \%$ Confidence Interval. The majority (79.3\%) of respondents were of the Ga-Adangme ethnic group, were in the 40-49 years age bracket (44.4\%) and married (70.8\%). Except for age group, marital status, ethnicity and number of biological children, all socio-demographic characteristics were significantly associated with prostate cancer screening uptake $(\mathrm{p}<0.05)$ but there was no significant association between socio-demographic characteristics and knowledge level on prostate cancer $(p>0.05)$. Only religious affiliation and family history of prostate cancer were significantly associated with perceptions on prostate cancer. The study showed that most men in the Lower Manya Krobo Municipality were aware of prostate cancer. This, however, did not translate into practice. Public health interventions should have Ministry of Health liaise with the National Health Insurance Scheme to roll out a free prostate cancer screening and prevention program in the District hospitals to ensure early screening.
\end{abstract}

Keywords: Prostate Cancer, Screening, Lower Manya Krobo Municipality, Ghana

\section{Introduction}

In recent times, prostate cancer $(\mathrm{PC})$ has made significant health impact globally, and Ghana is no exception. Researchers and health institutions continue to extensively report prostate cancer [1]. The incidence and mortality of prostate cancer worldwide correlate with increasing age, with the average age at the time of diagnosis being 66 years. For African-American men, the incidence rates are higher than White men, with 158.3 new cases diagnosed per 100,000 men and their mortality is approximately twice as White men [2]. The reasons for this disparity have been hypothesized to differences in social, environmental and genetic factors. According to Ferlay et al. (2019), an estimated 2,293,818 cases have been projected until 2040 with a small difference in mortality (an increase of $1.05 \%$ ) [3].

In Africa, the commonest type of cancer among men relating to both prevalence and mortality is prostate cancer. That is, the prevalence of all male cancer and mortalities associated with cancer is $40,000(13 \%)$ and $28,000(11.3 \%)$, respectively [4]. 
What accounts for this disparity could be attributable to the differences in testing, referral patterns, access to care, differences in the biology of the disease, inherited susceptibility, treatment options, reporting and diagnosis [5-6]. Due to early detection and treatment of prostate cancers, the rates of death have declined by 27\% each year between 1991 and 2016 [6]. Early detection is the result of lower mortality in high-income countries. In comparison, late-stage, incurable tumours suggest the need for education schemes and better services as identified in high-income countries [7].

Statistics show that prostate cancer is the second most common cancer in men, with more than 200 cases per 100,000 population per annum in Ghana [8]. About $75 \%$ of prostate cancer cases in hospitals have been reported in advanced stages, despite the high mortality rate associated with this disease [9]. While a higher understanding of prostate cancer among Nigerian men aged 50 and older was previously recorded, their level of information on the disease was poor (below 40\%) [10].

The American Cancer Society recommends that men over 50 years undergo either Prostate-Specific Antigen (PSA) or Digital Rectal Examination (DRE), prostate cancer screening every year. It further states that the advantages and disadvantages should be explained to patients before screening [11]. The study's main objective is to assess the knowledge and practices of prostate cancer screening uptake and its relationship with men's socio-demographic characteristics in the Lower Manya Krobo Municipality in the Eastern Region of Ghana.

\section{Methods}

\subsection{Profile of Study Site and Population}

The study was conducted within the Lower Manya Krobo Municipality. It is one of the 26 administrative districts in the Eastern Region of Ghana. The Municipality came into existence as a result of the split of the then Manya Krobo District into Lower and Upper Manya Krobo in 2008. It was elevated to a Municipality status in July 2012 by a Legislative Instrument (L.I.) 4026 with Odumase-Krobo as the capital [12]. This study's population was resident men aged 40 years and above who had made more than a year stay in the area. However, men aged 40 years and above with cognitive impairment and had not made a continued stay in the Municipality were excluded from participation.

\subsection{Study Design and Method}

The research design was a descriptive cross-sectional study among men in the Lower Manya Krobo Municipality. A quantitative approach was chosen employing a structured questionnaire to collect data on socio-demographic factors, practices of prostate cancer, knowledge about prostate cancer and early uptake of prostate cancer screening.

\subsection{Sample Size and Sampling Technique}

A sample size of about 346 men was estimated using the
Cochran formula [13] at $95 \%$ confidence interval and a $5 \%$ margin of error, considering a $65.2 \%$ prevalence rate for prostate cancer from literature.

$$
n=\frac{(Z)^{2} p(1-p)}{e^{2}}
$$

Where:

$\mathrm{n}=$ desired sample size

$\mathrm{Z}=$ reliability coefficient for a $95 \%$ confidence interval usually set at 1.96 .

$\mathrm{p}=$ the prevalence of prostate cancer was $65.2 \%$ [14].

$\mathrm{e}=$ degree of accuracy desired set at 0.05 probability level. Hence,

$$
n=\frac{(1.96)^{2} \times 0.652(1-0.652)}{(0.05)^{2}}=346.12
$$

Adding a 5\% non-response rate to the generated sample size, the operational size was brought to about 363 respondents. A multistage sampling method was employed over two months to select three hundred and sixty-three (363) respondents. A systematic selecting procedure with a chosen skip pattern was then used to pick study participants for enrolment after signing the consent form.

\subsection{Data Analysis}

STATA statistical software package (StataCorp.2007. Stata Statistical Software. Release 14. StataCorp LP, College Station, TX, USA) was used to clean, merge, and analyze the data from completed questionnaires. Univariate analysis was applied to establish the frequency and percentage distributions of the responses. Chi-square $\left(\chi^{2}\right)$ tests were employed to determine the association of selected variables with chosen response indicators. The threshold for statistical significance was set at a p-value less than 0.05 .

\subsection{Ethics}

Ethical clearance was sought from the Ethical Review Committee of Ensign College of Public Health. Administrative permission was also sought from the Lower Manya Krobo Municipality Health Directorate of Ghana Health Service (GHS) to collect data from the various communities in the Municipality. Participants were assured of confidentiality and privacy of the information provided.

\section{Results}

\subsection{Socio-demographic Characteristics of the Respondents}

The majority (79.3\%) of the respondents were of the GaAdangme ethnic group. The mean age of the respondents was $53.7 \pm 11.26$ years. A little over two-fifth of the respondents (44.4\%) were in the 40-49 years age bracket; 257 (70.8\%) were married, and the majority (93.1\%) reported to be Christians. The majority of the respondents, 167 (46.0\%) had attained JHS/Middle school education at the time of 
participation in the study. The informal or self-employment sector contributed the most $(58.1 \%)$ respondents, and about $15.0 \%$ were unemployed or pensioners. It was revealed that $44.9 \%$ had 1-3 children. The majority of the respondents $(80.7 \%)$ had no known family history of prostate cancer, and $73.5 \%$ indicated their NHIS card had expired (Table 1).

Table 1. Socio-Demographic Characteristics of Men in the LMKM.

\begin{tabular}{|c|c|c|}
\hline VARIABLES $(\mathrm{N}=363)$ & Frequency & Percentage \\
\hline \multicolumn{3}{|l|}{ Age group (yrs) } \\
\hline $40-49$ & 161 & 44.4 \\
\hline $50-59$ & 107 & 29.5 \\
\hline $60-69$ & 53 & 14.6 \\
\hline$>70$ & 42 & 11.5 \\
\hline \multicolumn{3}{|l|}{ Marital status } \\
\hline Single & 53 & 14.6 \\
\hline Married & 257 & 70.8 \\
\hline Divorced / Cohabiting/Widower & 53 & 14.6 \\
\hline \multicolumn{3}{|l|}{ Educational attainment } \\
\hline None & 39 & 10.7 \\
\hline JHS/Middle & 167 & 46.0 \\
\hline SHS/Voc/Tech & 59 & 16.3 \\
\hline Tertiary & 98 & 27.0 \\
\hline \multicolumn{3}{|l|}{ Religious affiliation } \\
\hline Christian & 338 & 93.1 \\
\hline Muslim & 18 & 5.0 \\
\hline Traditionalist & 7 & 1.9 \\
\hline \multicolumn{3}{|l|}{ Ethnicity } \\
\hline Ga-Adangme & 288 & 79.3 \\
\hline Ewe & 41 & 11.3 \\
\hline Akan & 24 & 6.6 \\
\hline Others & 10 & 2.8 \\
\hline \multicolumn{3}{|l|}{ Occupation } \\
\hline Informal/Self-Employed & 211 & 58.1 \\
\hline Formal/Government & 98 & 27.0 \\
\hline Unemployed/Pensioner & 54 & 14.9 \\
\hline \multicolumn{3}{|l|}{ Number of biological children } \\
\hline None & 39 & 10.7 \\
\hline $1-3$ & 163 & 44.9 \\
\hline $4-7$ & 133 & 36.6 \\
\hline $7+$ & 28 & 7.8 \\
\hline \multicolumn{3}{|l|}{$\begin{array}{l}\text { Family history of prostate } \\
\text { cancer (PC) }\end{array}$} \\
\hline Yes & 70 & 19.3 \\
\hline No & 293 & 80.7 \\
\hline \multicolumn{3}{|l|}{ valid NHIS card } \\
\hline Yes & 96 & 26.5 \\
\hline No & 267 & 73.5 \\
\hline Age $($ Mean \pm SD) & $53.7 \pm 11.26$ & \\
\hline
\end{tabular}

\subsection{Practices of Prostate Cancer Screening}

Most of the respondents $(92.0 \%)$ indicated hearing about prostate cancer; however, only a few $(17.0 \%)$ had been screened for it. The majority of the respondents $(85.1 \%)$ agreed that screening is essential and was not considered either painful (81.8\%) or embarrassing (85.9\%). While $88.4 \%$ of the respondents disagreed that screening for prostate cancer will aggravate the disease, $88.2 \%$ of the respondents indicated that screening would make them healthy. Additionally, $89.5 \%$ of the respondents stated that it was beneficial to screen for the disease to know their status and clear their doubts. Close to $70.0 \%$ of the respondents opined that it was not expensive to have regular prostate cancer screening (Table 2).

Table 2. Prostate Cancer Screening among Men in LMKM ( $n=363)$.

\begin{tabular}{lll}
\hline Variables & Freq. & Percentage \\
\hline Have you ever heard about PC? & 29 & 8.0 \\
No & 334 & 92.0 \\
Yes & & \\
Have you ever been screened for prostate cancer? & 302 & 83.2 \\
No & 61 & 16.8 \\
Yes & & \\
Is it important to screen for prostate cancer? & 309 & 85.1 \\
Agree & 54 & 14.9 \\
Don't know & & \\
Prostate cancer screening would be painful & 66 & 18.2 \\
Agree & 297 & 81.8 \\
Don't agree & & \\
Going through prostate cancer screening is embarrassing & \\
Agree & 51 & 14.1 \\
Don't agree & 312 & 85.9 \\
Prostate cancer screening will aggravate the disease & & \\
Agree & 42 & 11.6 \\
Don't agree & 321 & 88.4 \\
Going through PC screening will help me to be healthy & & \\
Agree & 320 & 88.2 \\
Don't agree & 43 & 11.8 \\
PC screening is beneficial and will settle any ambiguities about whether I \\
have the disease or not & 325 & 89.5 \\
Agree & 38 & 10.5 \\
Don't agree & & \\
Regular examination for prostate cancer is expensive & 115 & 31.7 \\
Agree & 248 & 68.3 \\
Don't agree & & \\
\hline
\end{tabular}

\subsection{Sources of Prostate Cancer Information and Types Screening}

Majority of the respondents heard of prostate cancer from television, radio and internet while $17.4 \%$ heard of prostate cancer from health workers. Also, 15.3\% indicated family and friends as their source of information about prostate cancer, and $11.0 \%$ of the respondents heard of prostate cancer from prostate cancer patients. The commonest form of prostate cancer screening done was Prostate-Specific Antigen (PSA) (79.0\%); followed by Digital Rectal Examination (DRE) (15.8\%) and Biopsy (5.2\%).

\subsection{Bivariate Association Between PC Screening Uptake and Selected Variables}

Except for the age group, marital status, ethnicity, and the number of biological children, all respondents' sociodemographic characteristics were identified to be significantly associated with prostate cancer screening uptake $(p<0.05)$. Respondents without any history of prostate cancer were more likely to take up prostate cancer screening than respondents with a family history of prostate cancer $(84.0 \%$ vs $16.0 \%, \mathrm{p}=0.001)$. Also, respondents with valid NHIS cards were more likely to take up prostate cancer screening than a respondent with invalid NHIS card $(71.8 \%$ vs $28.2 \%$, $\mathrm{p}=0.057$ ) (Table 3 ). 
Table 3. Bivariate analysis of Socio-Demographic Characteristics with prostate cancer Screening.

\begin{tabular}{|c|c|c|c|}
\hline \multirow{2}{*}{ Variables } & \multicolumn{2}{|c|}{ Prostate cancer screening uptake } & \multirow{2}{*}{ p-value } \\
\hline & No n (\%) & Yes n (\%) & \\
\hline Age group (in yrs) & & & 0.190 \\
\hline $40-49$ & $140(46.5)$ & $21(34.4)$ & \\
\hline $50-59$ & $88(29.2)$ & $18(29.5)$ & \\
\hline $60-69$ & $40(13.3)$ & $13(21.3)$ & \\
\hline$>70$ & $33(11.0)$ & $9(14.8)$ & \\
\hline Marital status & & & 0.121 \\
\hline Single & $40(13.2)$ & $13(21.3)$ & \\
\hline Married & $213(70.8)$ & $43(70.5)$ & \\
\hline Divorced/Cohabiting/Widower & $48(16.0)$ & $5(8.2)$ & \\
\hline Educational attainment & & & $0.018^{*}$ \\
\hline None & $36(12.0)$ & $3(4.9)$ & \\
\hline JHS/Middle & $145(48.2)$ & $21(34.4)$ & \\
\hline SHS/Voc/Tech & $47(15.6)$ & $12(19.7)$ & \\
\hline Tertiary & $73(24.2)$ & $25(41.0)$ & \\
\hline Religious affiliation & & & $0.032 *$ \\
\hline Christian & $283(94.0)$ & $54(88.5)$ & \\
\hline Muslim & $15(5.0)$ & $3(4.9)$ & \\
\hline Traditionalist & $3(1.0)$ & $4(6.6)$ & \\
\hline Ethnicity of respondents & & & 0.247 \\
\hline Ga-Adangme & $244(76.7)$ & $44(72.1)$ & \\
\hline Ewe & $31(10.3)$ & $10(16.4)$ & \\
\hline Akan & $19(6.3)$ & $4(6.6)$ & \\
\hline Others & $7(2.3)$ & $3(4.9)$ & \\
\hline Occupation & & & $0.053 *$ \\
\hline Informal/self-employed & $183(60.8)$ & $27(44.3)$ & \\
\hline Formal/government & $76(25.2)$ & $22(36.0)$ & \\
\hline Unemployed/pensioner & $42(14.0)$ & $12(19.7)$ & \\
\hline Number of biological children & & & 0.316 \\
\hline None & $30(10.0)$ & $9(14.8)$ & \\
\hline $1-3$ & $137(45.5)$ & $25(41.0)$ & \\
\hline $4-7$ & $108(35.9)$ & $25(41.0)$ & \\
\hline $7+$ & $26(8.6)$ & $2(3.2)$ & \\
\hline Family history of PC & & & $0.001 *$ \\
\hline No & $253(84.0)$ & $39(63.9)$ & \\
\hline Yes & $48(16.0)$ & $22(36.1)$ & \\
\hline Holder of valid NHIS card & & & 0.057 \\
\hline No & $85(28.2)$ & $10(16.4)$ & \\
\hline Yes & $216(71.8)$ & $51(83.6)$ & \\
\hline
\end{tabular}

\subsection{Knowledge of Prostate Cancer}

A majority $(75.2 \%)$ of the respondents were aware that prostate cancer is curable, with $83.5 \%$ disagreeing that it has no known cause. More than half of them $(64.2 \%)$ agreed that the disease might not present with early signs and symptoms, and $80.4 \%$ agreed that difficulty in urinating is one warning sign of disease. However, about $55.4 \%$ disagreed that weakness and numbness in the leg are signs of developing prostate cancer. On the one hand, $59.5 \%$ agreed that pain in the waist and back is a sign of developing prostate, while $51.5 \%$ of them agreed that men aged 40 years and below are at risk of developing prostate cancer. Furthermore, $62.0 \%$ of the respondents agreed that men with a family history of prostate cancer are more prone to suffering from the disease. More than half of the respondents $(54.8 \%)$ agreed that prostate cancer could be treated through surgery (Table 4).

Table 4. Knowledge of prostate cancer among men in LMKM ( $n=363)$.

\begin{tabular}{lcc}
\hline Variables & Freq. & Percentage \\
\hline Is prostate cancer curable? & 90 & 24.8 \\
No & 273 & 75.2 \\
Yes & 60 & 16.5 \\
Prostate cancer has no known cause? & 303 \\
Agree & 130 \\
Don't agree & 233.5 \\
PC may not present with signs and symptoms at the early stages? & 35.8 \\
Agree & 64.2 \\
Don't agree & 2 \\
\hline
\end{tabular}




\begin{tabular}{|c|c|c|}
\hline Variables & Freq. & Percentage \\
\hline Agree & 292 & 80.4 \\
\hline Don't agree & 71 & 19.6 \\
\hline \multicolumn{3}{|c|}{ Weakness and numbness in the leg and feet are warning sign of PC } \\
\hline Agree & 162 & 44.6 \\
\hline Don't agree & 201 & 55.4 \\
\hline \multicolumn{3}{|c|}{ Prostate cancer may present with pain in the waist and back } \\
\hline Agree & 216 & 59.5 \\
\hline Don't agree & 147 & 40.5 \\
\hline \multicolumn{3}{|c|}{ Men aged 40 and below are not at risk of developing PC than older men } \\
\hline Agree & 176 & 48.5 \\
\hline Don't agree & 187 & 51.5 \\
\hline \multicolumn{3}{|c|}{ Men who have a previous history of $\mathrm{PC}$ in the family are at high risk } \\
\hline Agree & 225 & 62.0 \\
\hline Don't agree & 138 & 38.0 \\
\hline \multicolumn{3}{|c|}{ Prostate-specific antigen (PSA) and Digital Rectal Examination (DRE) are screening methods for prostate cancer } \\
\hline Agree & 211 & 58.1 \\
\hline Don't agree & 152 & 41.9 \\
\hline \multicolumn{3}{|c|}{ Prostate cancer can be treated through surgery } \\
\hline Agree & 199 & 54.8 \\
\hline Don't agree & 164 & 45.2 \\
\hline
\end{tabular}

\subsection{Bivariate Association Between Knowledge of PC and Demographic Characteristics}

From the Chi-square tests on religious affiliation, the number of biological children, age group, marital status, educational attainment, ethnicity, occupation, family history of prostate cancer and valid NHIS cardholders were identified not to be significantly associated with knowledge level on prostate cancer $(p>0.05)$. Simply put, none of the observed socio-demographic characteristics of the respondents had any level of association with the knowledge level for screening for the disease condition (Table 5).

Table 5. Association between Socio-Demographic Characteristics and Knowledge on PC.

\begin{tabular}{|c|c|c|c|}
\hline \multirow{2}{*}{ Variables } & \multicolumn{2}{|c|}{ Knowledge on PC } & \multirow{2}{*}{ p-value } \\
\hline & Poor, n (\%) & Good, n (\%) & \\
\hline Age group (in yrs) & & & 0.348 \\
\hline $40-49$ years & $88(44.7)$ & $73(44.0)$ & \\
\hline $50-59$ years & $64(32.5)$ & $43(25.9)$ & \\
\hline $60-69$ years & $26(13.2)$ & $27(16.3)$ & \\
\hline$>70$ years & $19(9.6)$ & $23(13.9)$ & \\
\hline Marital status & & & 0.871 \\
\hline Single & 27 (13.7) & $26(15.7)$ & \\
\hline Married & $141(71.6)$ & $116(69.9)$ & \\
\hline Divorced / Cohabiting/Widower & $29(14.7)$ & $24(14.5)$ & \\
\hline Educational attainment & & & 0.104 \\
\hline None & $24(12.2)$ & $15(9.0)$ & \\
\hline JHS/Middle & $95(48.2)$ & $72(43.4)$ & \\
\hline SHS/Voc/Tech & $35(17.8)$ & $24(14.5)$ & \\
\hline Tertiary & $43(21.8)$ & $55(33.1)$ & \\
\hline Religious affiliation & & & 0.065 \\
\hline Christian & $178(90.3)$ & $160(96.4)$ & \\
\hline Muslim & $13(6.6)$ & $5(3.0)$ & \\
\hline Traditionalist & $6(3.1)$ & $1(0.6)$ & \\
\hline Ethnicity of respondents & & & 0.517 \\
\hline Ga Adangme & $154(78.2)$ & $134(80.7)$ & \\
\hline Ewe & $26(13.2)$ & $15(9.1)$ & \\
\hline Akan & $13(6.6)$ & $11(6.6)$ & \\
\hline Others & $4(2.0)$ & $6(3.6)$ & \\
\hline Occupation & & & 0.413 \\
\hline Informal/self-employed & $119(60.4)$ & $92(55.4)$ & \\
\hline Formal/government & $53(26.9)$ & $45(27.1)$ & \\
\hline Unemployed/pensioner & $25(12.7)$ & $29(17.5)$ & \\
\hline Number of biological children & & & 0.062 \\
\hline None & $20(10.2)$ & $19(11.4)$ & \\
\hline $1-3$ & $84(42.6)$ & $79(47.6)$ & \\
\hline $4-7$ & $71(36.0)$ & $62(37.4)$ & \\
\hline $7+$ & $22(11.2)$ & $6(3.6)$ & \\
\hline Family history of PC & & & 0.287 \\
\hline No & $163(82.7)$ & $130(78.3)$ & \\
\hline
\end{tabular}




\begin{tabular}{llll}
\hline \multirow{2}{*}{ Variables } & Knowledge on PC & & p-value \\
\cline { 2 - 3 } & Poor, $\mathbf{n}(\%)$ & Good, $\mathbf{n}(\%)$ & $36(21.7)$ \\
\hline Yes & $34(17.3)$ & & 0.059 \\
Holder of valid NHIS card & & $36(21.7)$ & \\
No & $60(30.5)$ & $130(78.3)$ & \\
Yes & $137(69.5)$ & & \\
\hline
\end{tabular}

\subsection{Perception of Prostate Cancer}

More than half of the respondents (55.1\%) agreed that prostate cancer is not sexually transmitted. However, $89.3 \%$ agreed that prostate cancer could kill, but once prostate cancer is treated, $83.5 \%$ agreed that living a normal life is guaranteed. About five (5) out of ten respondents (52.6\%) believed they were not at risk of getting prostate cancer, $81.8 \%$ believed being diagnosed with prostate cancer is not a 'death warrant'. Although most of them $(90.9 \%)$ disagreed that prostate cancer is a taboo or a curse; $87.3 \%$ believed the disease is curable when detected early. Most of them $(71.9 \%)$ agreed that ageing is a risk factor. The majority (71.1\%) disagreed that prostate cancer is painful and discourages early seeking treatment. Also, $75.8 \%$ did not perceive regular prostate cancer screening as an indication of suffering from prostate cancer (Table 6).

Table 6. Perception on Prostate Cancer among Men in LMKM ( $n=363)$.

\begin{tabular}{|c|c|c|}
\hline Variables & Freq. & Percentage \\
\hline \multicolumn{3}{|c|}{ Prostate cancer cannot be sexually transmitted } \\
\hline Agree & 200 & 55.1 \\
\hline Don't agree & 163 & 44.9 \\
\hline \multicolumn{3}{|c|}{ Prostate cancer can lead to death } \\
\hline Agree & 324 & 89.3 \\
\hline Don't agree & 39 & 10.7 \\
\hline \multicolumn{3}{|c|}{ One can live a normal life after treatment of prostate cancer } \\
\hline Agree & 303 & 83.5 \\
\hline Don't agree & 60 & 16.5 \\
\hline \multicolumn{3}{|c|}{ I believe I am at high risk of getting prostate cancer } \\
\hline Agree & 172 & 47.4 \\
\hline Don't agree & 191 & 52.6 \\
\hline \multicolumn{3}{|c|}{ I believe that if you are diagnosed with prostate cancer, then you are doomed to die. } \\
\hline Agree & 66 & 18.2 \\
\hline Don't agree & 297 & 81.8 \\
\hline \multicolumn{3}{|c|}{ Prostate cancer is a result of a curse and seen as a taboo } \\
\hline Agree & 33 & 9.1 \\
\hline Don't agree & 330 & 90.9 \\
\hline \multicolumn{3}{|c|}{ Prostate cancer has no cure even when it is detected early } \\
\hline Agree & 46 & 12.7 \\
\hline Don't agree & 317 & 87.3 \\
\hline \multicolumn{3}{|c|}{ One is more likely to contract the disease after 50 yrs? } \\
\hline Agree & 261 & 71.9 \\
\hline Don't agree & 102 & 28.1 \\
\hline \multicolumn{3}{|c|}{ PC treatment is painful, and it deters affected persons from seeking timely treatment } \\
\hline Agree & 105 & 28.9 \\
\hline Don't agree & 258 & 71.1 \\
\hline \multicolumn{3}{|c|}{ Regular check-up for prostate cancer indicates that one has prostate cancer } \\
\hline Agree & 88 & 24.2 \\
\hline Don't agree & 275 & 75.8 \\
\hline \multicolumn{3}{|c|}{ Prostate cancer can be treated when found early } \\
\hline Agree & 333 & 91.7 \\
\hline Don't agree & 30 & 8.3 \\
\hline
\end{tabular}

\subsection{Bivariate Association Between Perception on Prostate Cancer and Socio-demographic Characteristics}

Statistical tests for associations on age group, marital status, ethnicity, occupation, number of biological children, and holders of valid NHIS cards were identified not to be significant with perception on prostate cancer. Religious affiliation and family history of prostate cancer were significantly associated with the perception of prostate cancer $(\mathrm{p}<0.05)$. Perception on prostate cancer was significantly higher among JHS/Middle Schools leavers than those without formal education $(53.1 \%$ vs $9.5 \%, \quad \mathrm{p}=0.064)$. Christians were identified as having a significantly good perception of prostate cancer compared to Muslims (98.3\% vs $1.7 \%, p=0.000)$. Respondents who had a family history of prostate cancer were identified to have significantly good perceptions than respondents without prostate cancer history in their families ( $78.3 \%$ vs ns $21.7 \%, \mathrm{p}=0.012)$ (Table 7). 
Table 7. Bivariate Test for Association between Socio-Demographic Characteristics and Respondents' Perception of Prostate Cancer.

\begin{tabular}{|c|c|c|c|}
\hline \multicolumn{4}{|c|}{ Perception on prostate cancer } \\
\hline Variables & Poor, n (\%) & Good, n (\%) & p-value \\
\hline Age group (in yrs) & & & 0.267 \\
\hline $40-49$ & $85(46.2)$ & $76(42.5)$ & \\
\hline $50-59$ & $59(32.1)$ & $48(26.8)$ & \\
\hline $60-69$ & $22(12.0)$ & $31(17.3)$ & \\
\hline$>70$ & $18(9.8)$ & $24(13.4)$ & \\
\hline Marital status & & & 0.240 \\
\hline Single & $31(16.9)$ & $22(12.3)$ & \\
\hline Married & $123(66.9)$ & $134(74.9)$ & \\
\hline Divorced / Cohabiting/Widower & $30(16.2)$ & $23(12.8)$ & \\
\hline Educational attainment & & & 0.064 \\
\hline None & $22(12.0)$ & $17(9.5)$ & \\
\hline JHS/Middle & $72(39.1)$ & $95(53.1)$ & \\
\hline SHS/Voc/Tech & $35(19.0)$ & $24(13.4)$ & \\
\hline Tertiary & $55(29.9)$ & $43(24.0)$ & \\
\hline Religious affiliation & & & $0.000 *$ \\
\hline Christian & $162(88.0)$ & $176(98.3)$ & \\
\hline Muslim & $15(8.2)$ & $3(1.7)$ & \\
\hline Traditionalist & $7(3.8)$ & $0(0.0)$ & \\
\hline Ethnicity of respondents & & & 0.842 \\
\hline Ga Adangme & $143(72.8)$ & $145(77.1)$ & \\
\hline Ewe & $22(12.0)$ & $19(10.6)$ & \\
\hline Akan & $14(7.6)$ & $10(5.6)$ & \\
\hline Others & $5(2.7)$ & $5(2.8)$ & \\
\hline Occupation & & & 0.528 \\
\hline Informal/self-employed & $102(55.4)$ & $109(60.9)$ & \\
\hline Formal/government & $54(29.4)$ & $44(24.6)$ & \\
\hline Unemployed/pensioner & $28(15.2)$ & $26(14.5)$ & \\
\hline Number of biological children & & & 0.379 \\
\hline None & $24(13.0)$ & $15(8.4)$ & \\
\hline $1-3$ & $76(41.3)$ & $87(48.6)$ & \\
\hline $4-7$ & $69(37.5)$ & $64(35.8)$ & \\
\hline $7+$ & $15(8.2)$ & $13(7.3)$ & \\
\hline Family history of PC & & & $0.012 *$ \\
\hline Yes & $158(85.9)$ & $135(75.4)$ & \\
\hline No & $26(14.1)$ & $44(24.6)$ & \\
\hline Holder of valid NHIS card & & & 0.302 \\
\hline No & $53(28.8)$ & $43(24.0)$ & \\
\hline Yes & $131(71.2)$ & $136(76.0)$ & \\
\hline
\end{tabular}

Statistically significant at $\alpha=0.05$

\subsection{Multivariate Association Between Dependent and Independent Variable}

There was a significant and progressive likelihood of involvement in practices on the disease with age. Respondents aged 60-69 years were about 5.74 times more likely to engage in good prostate cancer practices compared to their counterparts in the 40-49year age bracket (AOR: 5.74, 95\% CI: 1.96.16.77) after adjusting for all other covariates in the model. No significant association was observed between age group and knowledge and perception of prostate cancer. Marital status was identified to be significantly associated with practices of prostate cancer. Respondents who were divorced/cohabiting/widowed were 0.88 times less likely to engage in good prostate cancer practices compared to those married (AOR: $0.12,95 \% \mathrm{CI}$ : $0.03,0.48)$. No significant association was observed between marital status and knowledge and perception of prostate cancer. Educational attainment was identified to be significantly associated with practices and knowledge of prostate cancer. Respondents with tertiary education were 5.29 times more likely to engage in good prostate cancer practices compared to those with their counterparts with no formal educational exposure (AOR: 5.29, (1.02,27.30). Furthermore, respondents with tertiary education were 3.43 times more likely to have adequate knowledge of prostate cancer than those with less educational qualification (AOR:3.43, 95\% CI: 1.23, 9.59) holding all other variables constant. No significant association was observed between educational attainment and the perception of prostate cancer.

Traditional worshippers were 0.89 times less likely to have good knowledge on prostate cancer compared to the Christian counterparts (AOR: 0.11, 95\% CI: 0.01, 1.19). Conversely, they show a very significant likelihood to engage in good practices around the disease. Similarly, there was 0.76 times less likely chance for a Muslim to have a good perception on prostate cancer compared to a respondent who professed faith in Christianity (AOR: 0.24, 95\% CI: 0.06, 0.93). 
Formal/government employees were 0.51 times less likely to have good knowledge on prostate cancer compared to respondents in the informal sector (AOR: 0.49, 95\% CI: 0.24, 1.01) holding all other variables constant. Again, there was 0.62 times less likely chance for formal/government employees to have a good perception on prostate cancer compared to others (AOR: 0.38, 95\% CI: 0.14, 1.02).

Also, respondents with seven children and more were 0.80 times less likely to engage in good prostate cancer practices compared with their colleagues who reported not having any biological children at the time of the study (AOR: 0.20, 95\% CI: $0.03,1.47)$. Conversely, there was 0.79 times less likely chance for respondents with seven children and more to have good knowledge on prostate cancer compared to others (AOR: 0.21, 95\% CI: 0.06, 0.74).

Respondents with a family history of prostate cancer were 4.05 times more likely to engage in good prostate cancer practices compared to respondents with no family history of prostate cancer (AOR: 4.05, 95\% CI: 2.01, 8.19). Yet again, respondents with a family history of prostate cancer were 2.21 times more likely to have a good perception on prostate cancer compared to those with no trace of the disease in their families (AOR: 2.21, 95\% CI: 1.24, 3.94). Holding a valid NHIS card has no significant effect on the likelihood of either engaging in good practices, having high knowledge or good perception on prostate cancer (Table 8).

Table 8. Multivariate Logistic Regression of Practices, Knowledge and Perception on PC with Socio-Demographic Characteristics.

\begin{tabular}{|c|c|c|c|c|c|c|}
\hline \multirow{2}{*}{ Variables } & \multicolumn{2}{|l|}{ Practices of PC } & \multicolumn{2}{|c|}{ Knowledge on PC } & \multicolumn{2}{|l|}{ Perception on PC } \\
\hline & $\operatorname{AOR}(95 \% C I)$ & $\operatorname{COR}(95 \% \mathrm{CI})$ & $\operatorname{AOR}(95 \% \mathrm{CI})$ & $\operatorname{COR}(95 \% \mathrm{CI})$ & $\operatorname{AOR}(95 \% C I)$ & $\operatorname{COR}(95 \% \mathrm{CI})$ \\
\hline \multicolumn{7}{|l|}{ Age group } \\
\hline $40-49$ years & Ref & Ref & Ref & Ref & Ref & Ref \\
\hline $50-59$ years & $2.36(1.07,5.21)$ & $1.36(0.69,2.70)$ & $0.96(0.56,1.65)$ & $0.81(0.49,1.33)$ & $0.84(0.49,1.45)$ & $0.91(0.56,1.49)$ \\
\hline $60-69$ years & $5.74(1.96,16.77)$ & $2.17(0.99,4.71)$ & $1.91(0.84,4.33)$ & $1.25(0.67,2.33)$ & $2.61(1.11,6.11)$ & $1.58(0.84,2.95)$ \\
\hline$>70$ years & $7.84(1.86,33.04)$ & $1.82(0.76,4.33)$ & $2.55(0.85,7.02)$ & $1.46(0.74,2.89)$ & $3.37(1.13,10.02)$ & $1.49(0.75,2.96)$ \\
\hline \multicolumn{7}{|l|}{ Marital status } \\
\hline Married & $0.39(0.16,0.94)$ & $0.62(0.31,1.26)$ & $0.77(0.39,1.50)$ & $0.85(0.47,1.54)$ & $1.38(0.70,2.73)$ & $1.54(0.84,2.79)$ \\
\hline Divorced/Cohabiting/Widower & $0.12(0.03,0.48)$ & $0.32(0.11,0.98)$ & $0.89(0.38,2.10)$ & $0.86(0.40,1.84)$ & $1.00(0.42,2.42)$ & $1.08(0.50,2.33)$ \\
\hline \multicolumn{7}{|l|}{ Educational attainment } \\
\hline None & Ref & Ref & Ref & Ref & Ref & Ref \\
\hline JHS/Middle & $2.45(0.55,10.88)$ & $1.74(0.49,6.15)$ & $1.27(0.58,2.77)$ & $1.21(0.59,2.48)$ & $1.51(0.68,3.33)$ & $1.71(0.85,3.45)$ \\
\hline SHS/Voc/Tech & $4.76(0.96,23.70)$ & $3.06(0.86,11.67)$ & $1.16(0.46,2.93)$ & $1.11(0.48,2.51)$ & $0.91(0.35,2.35)$ & $0.89(0.39,2.01)$ \\
\hline Tertiary & $5.29(1.02,27.30)$ & $4.11(1.16,14.52)$ & $3.43(1.23,9.59)$ & $2.05(0.96,4.37)$ & $1.04(0.37,2.87)$ & $1.01(0.48,2.14)$ \\
\hline Christian & Ref & Ref & Ref & Ref & Ref & Ref \\
\hline Muslim & $1.96(0.42,9.23)$ & $1.05(0.29,3.74)$ & $0.41(0.12,1.36)$ & $0.43(0.15,1.23)$ & $0.24(0.06,0.93)$ & $0.18(0.05,0.65)$ \\
\hline Traditionalist & $30.90(4.03,236.72)$ & $6.99(1.52,32.11)$ & $0.11(0.01,1.19)$ & $0.19(0.02,1.56)$ & - & - \\
\hline \multicolumn{7}{|l|}{ Occupation } \\
\hline Informal/self-employed & Ref & Ref & Ref & Ref & Ref & Ref \\
\hline Formal/government & $1.44(0.59,3.49)$ & $1.96(1.05,3.66)$ & $0.49(0.24,1.01)$ & $1.10(0.68,1.78)$ & $0.79(0.39,1.58)$ & $0.76(0.47,1.23)$ \\
\hline Unemployed/pensioner & $0.52(0.15,1.84)$ & $1.94(0.91,4.13)$ & $0.67(0.26,1.71)$ & $1.50(0.82,2.73)$ & $0.38(0.14,1.02)$ & $0.87(0.48,1.58)$ \\
\hline \multicolumn{7}{|l|}{ Number of biological children } \\
\hline None & Ref & Ref & Ref & Ref & Ref & Ref \\
\hline $1-3$ & $0.88(0.29,2.71)$ & $0.61(0.26,1.43)$ & $0.73(0.32,1.63)$ & $0.99(0.49,1.99)$ & $0.97(0.42,2.21)$ & $1.83(0.90,3.74)$ \\
\hline $4-7$ & $1.10(0.33,3.70)$ & $0.77(0.33,1.83)$ & $0.69(0.29,1.65)$ & $0.92(0.45,1.88)$ & $0.63(0.26,1.53)$ & $1.48(0.72,3.10)$ \\
\hline $7+$ & $0.20(0.03,1.47)$ & $0.26(0.05,1.30)$ & $0.21(0.06,0.74)$ & $0.29(0.10,0.86)$ & $0.63(0.20,2.02)$ & $1.39(0.52,3.71)$ \\
\hline \multicolumn{7}{|l|}{ Family history of PC } \\
\hline No & Ref & Ref & Ref & Ref & Ref & Ref \\
\hline Yes & $4.05(2.01,8.19)$ & $2.97(1.62,5.46)$ & $1.40(0.80,2.45)$ & $1.33(0.79,2.24)$ & $2.21(1.24,3.94)$ & $1.98(1.16,3.39)$ \\
\hline \multicolumn{7}{|l|}{ Holder of valid NHIS card } \\
\hline
\end{tabular}

COR, Crude odds ratio; CI, Confidence interval; AOR, Adjusted odds ratio, Ref, Reference category

\section{Discussion}

\subsection{Characteristics of Respondents}

The knowledge level, perception and practices of prostate cancer screening uptake among men aged 40 years and above were examined in this study as against other studies that focused mainly on hospital-based settings. This group was targeted because they are at a higher risk of developing the condition than their younger counterpart. Though prostate cancer's exact cause/s remains unknown, old age is considered a risk factor [15]. Subsequently, men in the Municipality, who are particularly aware of their prostate cancer status, are good candidates to serve as ambassadors, educators, advocates and role models to influence their communities in promoting prostate cancer screening uptake and prevention to reduce the associated morbidity and mortality.

The perceived values and beliefs among the study participants can prevent early prostate cancer screening uptake. This is very worrying because it can influence the 
understanding and health-seeking behaviour if one test positive for the disease. Similarly, religion can negatively impact the early uptake of prostate cancer screening as explained by Pedersen et al., (2012) that the perception of fears and taboos among people of a particular ethnic descent affects its men's willingness to talk to their doctors about prostate cancer [16]. The belief of some men in God's healing power supersedes the potency of the health system, thus relying more on spirituality to be "free" from developing prostate cancer than screening to know their status.

From the study, it was observed that the highest attainable level of education by most $(46.0 \%)$ of the respondents at the time of participation was JHS/Middle school. This is an indication of formal education and by extension, the ability to read and make informed decisions. Taking up early prostate cancer screening or seeking early treatment can be influenced by formal educational attainment.

Also, occupation can be a predisposing factor for developing prostate cancer based on the nature of work. Engaging in sedentary work can be psychologically draining as exercises are non-existent in the daily lives of the study participants. For example, an occupational lifestyle which permits carrying mobile phones in the pocket for longer days increases the risk of prostate cancer [17]. There is also an unconventional knowledge that presupposes that prostate cancer is more likely to rear its head among men who are not sexually active. This agrees with Etawo et al. (2012) that elevated levels of testosterone and decreased levels of oestradiol in the blood are risk factors for developing prostate cancer [18]. Another school of thought has it that, having several sexual partners can lead to developing prostate cancer [7].

One common way of developing prostate cancer is through heredity. Due to the 'transfer' of chromosomes from parents to children, being born into families with a history of prostate cancer makes it more likely for one to develop the condition [19]. Considering the high cost of seeking medical care in Ghana, the NHIS was introduced to alleviate the burden of the 'poor'; however, the failure to renew NHIS cards hampers regular check-ups, a situation that contributes to late screening for prostate cancer among the respondents in this study and possibly, its treatment.

\subsection{Practices of Prostate Cancer}

Generally, self-reported practices of prostate cancer were good; however, uptake of prostate cancer screening was low, with just about two (2) out of ten respondents self-reporting to have ever been screened for prostate cancer. This is consistent with a study undertaken in Australia which reported that men have a negative attitude towards screening for prostate cancer due to reasons such as the uncomfortable nature of Digital Rectal Examination (DRE) and the blood drawn for Prostate Specific Antigen (PSA) [20]. The low prostate cancer screening can exacerbate the rate at which patients can be treated and prevent other comorbidities thereof. This is evident by screening in the asymptomatic stages and early therapies for the reduction of deaths due to breast, lung, colon and cervical cancers [21]. The low uptake of prostate cancer screening in the LMKM among men aged 40 years and above irrespective of the good self-reported practices can partly be ascribed to low knowledge on the screening guidelines as well as the absence of a well laid out program targeting them at no cost.

Additionally, religious affiliation, educational attainment, occupation, family history of prostate cancer and valid NHIS cardholders were identified to be significantly associated with practices of prostate cancer screening uptake among the studied population. On the one hand, the role of religious beliefs and church support were identified as important in prostate cancer prevention and screening behaviours among African-American men [22]. Religious beliefs are the most common reasons for non-participation in prostate cancer screening in Sub-Saharan Africa [23]. In Nigeria as well, religion influences beliefs and this in turn influence health behaviour in taking up early screening [24]. Educational attainment was identified to be significantly associated with a higher proportion of prostate cancer screening uptake. The lack of information on prostate cancer screening uptake as reported by Agbugui et al., (2013) is due to complete lack of information about risk factors, signs and symptoms [25]. This is an indication that being educated formally makes prostate cancer screening an easy decision. Thus, information on the dangers of the disease is easy to understand in order to take up the screening to know their status. Hence, an intervention aimed at ensuring regular uptake of screening can target these 'educated' men to disseminate among their peers. This is because a high level of awareness on the importance of prostate cancer screening is associated with a high level of formal education.

Additionally, respondents' occupation was identified to be associated with a higher proportion of prostate cancer screening uptake. This is consistent with a study done in Nigeria by Oranusi et al., (2012) which reported that the majority of public servants correctly reported one or more prostate cancer symptoms with the most common symptom found being the difficulty in urinating [26]. To become a public servant or government employee, it is expected that one possesses some level of formal education, hence, implementation of institutional/occupational programs to promote early and sustained screening would probably assist in increasing awareness on the early uptake of prostate cancer screening and hopefully translate into improving their ability to educate other men in the community.

Respondents with a reported family history of prostate cancer were about four (4) times more likely to take up prostate cancer screening than respondents without a family history of prostate cancer. There is evidence that people with a family history of prostate cancer are at risk for the disease [15]. This suggests that there is a high level of awareness among men with a family history of prostate cancer to take up early screening [27]. There is some level of ease with which men with a family history of the disease take up prostate cancer screening as they age older in order to know their status and to seek early treatment. Alternatively, there is a low level of urgency among men without a family history to take up early prostate cancer 
screening because of their lack of knowledge on the dangers the disease has on their well-being. Also, respondents with valid National Health Insurance Scheme (NHIS) cards were more likely to take up prostate cancer screening compared with the respondents with invalid NHIS cards. This is in line with the International Network for Cancer Treatment and Research [INCTR], (2013) findings which concluded that health care and cancer management program and government fund for health care expenditure is crucial for better healthcare delivery [28]. The NHIS was instituted to cut down the high cost of seeking medical care; thus, there is an increased chance of men with valid NHIS cards to take up routine screening particularly when they do not pay for the consultation. There are enough health professionals who have expertise in prostate cancer care while most hospitals have effective prostate cancer screening programs, but the problem remains the fact that the PSA test has not been enrolled onto the National Health Insurance Scheme thus, making it impossible for most men to get screened. To increase prostate cancer awareness, the cost of screening must be "captured" in the National Health Insurance Scheme. This will increase enrollment and the uptake of screening among men aged 40 years and above. The majority of the men in this study heard of prostate cancer from television, radio and internet while $17.4 \%$ heard of prostate cancer from health workers similar to other studies in which most of the respondents obtained their information from health professionals, the media and friends or relatives [29-31]. Only 5.2\% of the men in this study had taken up Biopsy, a type of prostate cancer screening test. This further elucidates the poor prostate cancer screening uptake among men in LMKM.

\subsection{Knowledge on Prostate Cancer}

Generally, the level of knowledge of men in LMKM on prostate cancer was good; thus, $75.2 \%$ of the respondents were aware that prostate cancer is curable. This is similar to previous studies which reported a high degree of awareness about prostate cancer $[26,27]$ but contrary to previous studies which reported low levels of knowledge about prostate cancer in Australia [20], United States of America [16, 32], Uganda [7] and Nigeria [25]. Knowledge on prostate cancer among men in this study was enough, contrary to findings from previous studies that concluded that the general public knew little about prostate cancer [7, 16]. There has been a lack of information or understanding of the availability of screening or testing for prostate cancer in some studies $[33,34]$, which is one of the reasons why most cases of prostate cancer are reported in advanced stages.

Though the knowledge of men on prostate cancer was good, knowledge on the screening guidelines was low, a situation that affects early uptake of prostate cancer screening. This is troubling because it might impact negatively on their ability to 'spread' or educate other men on the need and significance of getting screened as previous studies have demonstrated that knowledge is a powerful and an effective 'weapon' in the reduction, prevention and early detection of prostate cancer among men [35]. The 'adequacy' of knowledge among men in this study is attributable to the protracted and sustained information sharing on the traditional media and information centres by local drug manufacturers and sellers targeting men in the informal sector with the belief that they do not have enough knowledge. Likewise, most educational programs on prostate cancer are community-based or targeted at the general population. This may also explain the quality of knowledge men in LMKM have on prostate cancer. More importantly, religious affiliation, number of biological children, age group, marital status, educational attainment, ethnicity, occupation, family history of prostate cancer and valid NHIS cardholders were identified not to be significantly associated with knowledge level on prostate cancer screening uptake among men in the LMKM. This indicates that prostate cancer knowledge is hinged on men's personal characteristics in this study. Adequate knowledge level on the disease can positively impact the readiness and confidence of other men with lower educational attainment levels to take up an early screening to reduce morbidity and mortality.

\subsection{Perception on Prostate Cancer}

There was a general positive perception of the significance of prostate cancer screening in plummeting the disease among men in LMKM with $55.1 \%$ of them positively perceiving that prostate cancer is not a sexually transmitted infection and $90.9 \%$ who did not consider the disease a taboo. This is consistent with previous studies' findings [7, 17]. Additionally, educational attainment, religious affiliation, and family history of prostate cancer were significantly associated with prostate cancer perception. The perception of prostate cancer was significantly higher among JHS/Middle Schools leavers compared to those without formal education. This creates the impression that there is inadequate exposure, in terms of good perception, on prostate cancer among men without any formal education. The perception of the risk of developing prostate cancer is influenced by educational attainment and personal experience [36].

Christians were identified to have a significantly good perception of prostate cancer compared to Muslims. This is contrary to the conclusion reached by Pedersen et al. (2012) that the perceptions of fears and taboos affect men's willingness to talk to their doctors about prostate cancer [16]. In addition, religious and cultural beliefs were the most common reasons for non-participation in prostate cancer screening [37]. However, this study's findings are in line with a study by Holt et al. (2009), which stressed the role of religious beliefs and church support in prostate cancer prevention and screening behaviours. Similarly, it was concluded in a study that examined the role of religious involvement with regard to prostate cancer screening that, those with religious affiliations were more likely to participate in screening than those without religious affiliations [22]. 


\section{Conclusion}

The practice of being screened for prostate cancer among men aged 40 years and above in LMKM was good. However, just about two out of ten respondents self-reported to have ever been screened for prostate cancer. Respondents who were affiliated with a religion, had a formal education, were governmental workers, had a family history of prostate cancer and were valid NHIS cardholders underwent more screening for prostate cancer in the LMKM. Generally, the level of knowledge of men in Lower Manya Krobo Municipality on prostate cancer was good, with a more significant number of them aware that the disease is curable. This notwithstanding, specific knowledge on the screening guidelines was low. The personal characteristics were identified as not significantly associated with knowledge level on prostate cancer screening uptake among men in the Lower Manya Krobo Municipality. There was a general positive perception of the significance of prostate cancer screening in plummeting the disease among men in LMKM with $55.1 \%$ of them positively perceiving prostate cancer as not being a sexually transmitted infection and 90.9\% not considering the disease as a taboo.

\section{Authors' Contributions}

This work was carried out in collaboration with all authors. VNL and SM participated in conceiving the study and in the development of data collection tools. VNL carried out data collection. VNL and SM participated in the data analysis and drafting of the manuscript. All authors read and approved the final manuscript.

\section{Conflict of Interest}

All the authors do not have any possible conflicts of interest.

\section{References}

[1] Bray F, Ferlay J, Soerjomataram I, Siegel RL, Torre LA, \& Jemal A. (2018). Global cancer statistics 2018: GLOBOCAN estimates of incidence and mortality worldwide for 36 cancers in 185 countries. CA Cancer $J$ Clin; 68(6):394-424. https://doi.org/10.3322/caac.21492

[2] Panigrahi, G. K., Praharaj, P. P., Kittaka, H., Mridha, A. R., Black, O. M., Singh, R., Mercer, R Deep, G. (2019). Exosome proteomic analyses identify inflammatory phenotype and novel biomarkers in African American prostate cancer patients. Cancer $\quad$ Med (3):1110-1123. https://doi.org/10.1002/cam4.1885

[3] Ferlay, J., Lam, F., Colombet, M., Mery, L., Pineros, M., Znaor, A., Soerjomataram, I. et al., Global Cancer observatory: Cancer Today. Lyon, France: International Agency for Research on Cancer. Retrieved on 02/02/2019 from: https://geo.iarc.fr/today

[4] Akemi, T., Ogo, C. N. \& Olutunde, A. O. (2011). Review of prostate cancer research in Nigeria: Infectious agent cancer. Biomed Central. 6 (2): S8 https://doi.org/10.1186/1750-93786-s2-s8

[5] Odedina F. T, Ogunbiyi J. O \& Ukoli F. A. M (2006). Roots of prostate cancer in African-American men. J Natl Med Assoc, 98, 539-43. https://pubmed.ncbi.nlm.nih.gov/16623066/

[6] American Cancer Society (ACS) (2016). Cancer facts and figures 2016, pp 1-9. https://www.cancer.org/research/cancerfacts-statistics/all-cancer-facts-figures/cancer-facts-figures2016.html

[7] Nakandi H, Kirabo M. \& Semugabo C. (2013). Knowledge, attitudes and practices of Ugandan men regarding prostate $\begin{array}{lllll}\text { cancer. } & A f r & J & \text { Urol, } & 19,\end{array}$ https://doi.org/10.1016/j.afju.2013.08.001

[8] Ministry of Health \& Ghana Health Service (MOH/GHS), (2014). National strategy for cancer control in Ghana, 20142017, Accra, Ghana: Adwinsa. https://www.iccpportal.org/system/files/plans/Cancer\%20Plan\%20Ghana\%20 Ministry $\% 20 \mathrm{of} \% 20 \mathrm{Health} . \mathrm{pdf}$

[9] Yamoah, K., Beechman, K., Hegarty, S. \& Hyslop, T. (2013). Early results of prostate cancer radiation therapy: An analysis with emphasis on research strategies to improve treatment delivery and outcomes. BMC Cancer 13(1):23 https://doi.org/10.1186/1471-2407-13-23

[10] Oladimeji O, Bidemi Y. O, Olufisayo, J. A. Y \& Sola A. O. (2010). Prostate cancer awareness, knowledge, and screening practices among older men in Oyo State, Nigeria. Int $Q$ Community Health Educ, 30, 271-86. https://doi.org/10.2190\%2FIQ.30.3.g

[11] Tasian, G. E., Cooperberg, M. R., Cowan, J. E., Keyashian, K., Greene, K. L., Daniels, N. A., Chan, J. M. (2012). Prostate-specific antigen screening for prostate cancer: knowledge of, attitudes towards, and utilization among primary care physicians. Urologic Oncology, 30(2), 155-60. https://doi.org/10.1016/j.urolonc.2009.12.019

[12] Ghana Statistical Service: National Population and Census Report (2010). https://www2.statsghana.gov.gh/docfiles/2010_District_Repor t/Eastern/LOWER\%20MANYA\%20KROBO.pdf

[13] Cochran, W. C. (1977) 'Snedecor G W \& Cochran W G. Statistical methods applied to experiments in agriculture and biology. 5th ed. Ames, Iowa: Iowa State University Press, 1956.', Citation Classics, 19(19), p. 1.

[14] Alexander Egote, P P S Ossei, W G Ayibor. (2018): Patterns and presentation of prostate cancer at a referral hospital in the Brong Ahafo region of Ghana: A 10-year retrospective study. Healthy Aging Research. 9 (5) https://www.longdom.org/articles/patterns-and-presentationof-prostate-cancer-at-a-referral-hospital-in-the-brong-ahaforegion-of-ghana-a-10year-retrospe.pdf

[15] America Cancer Society (ACS), (2014). Prostate Cancer: What is cancer? Accessed on 12/05/2019 from http://www.cancer.org/acs/groups/cid/documents/webcontent/ 003134-pdf.pdf

[16] Pedersen, V. H., Armes, J., \& Ream, E. (2012). Perceptions of prostate cancer in Black African and Black Caribbean men: A systematic review of the literature. Psycho-Oncology, 468(September 2011), 457-468. https://doi.org/10.1002/pon.2043 
[17] Fitzpatrick, J. M., Kirby, R. S., Brough, C. L., \& Saggerson, A. L. (2009). Awareness of PC among patients and the general public: Results of an international survey. $P C$ and Prostatic Diseases, $12(4)$,

https://dx.doi.org/10.1038\%2Fpcan.2009.30

$347-54$

[18] Etawo, U. S., Ekeke, N. O., \& Mbiaba, A. B. (2012). Prospective study of sex hormone levels among prostate cancer patients attending the University of Port Harcourt Teaching Hospital clinic. The Nigerian Health Journal, 12(2), 39-42. https://www.ajol.info/index.php/nhj/article/view/81256

[19] Leitzmann, M. F. \& Rohrmann, S. (2012). Risk factors for the onset of prostatic cancer: age, location, and behavioral correlates. Clinical Epidemiology, 4 1-11 https://dx.doi.org/10.2147\%2FCLEP.S16747

[20] Sanderson, R., Wijesinha, S. S., \& Jones, K. M. (2013). What men know about the symptoms and treatment of PC: A study comparing ADF and civilian men? Journal of Military and Veterans' Health, 21(3), 4-13.

[21] Kolahdooz, F., Jang, S. L., Corriveau, A., Gotay, C., Johnston, N., \& Sharma, S. (2014). Knowledge, attitudes, and behaviours towards cancer screening in indigenous populations: A systematic review. The Lancet: Oncology, 15(11), e504-e516. https://doi.org/10.1016/s14702045(14)70508-x

[22] Holt. A., Cheryl, L., Theresa. A., Wynn, \& Jasmine, D. (2009). Religious involvement and Prostate Cancer Screening behaviours among South-eastern African American Men. American Journal of Men's Health. 3(3): 3214-223. https://doi.org/10.1177/1557988308318686

[23] Rebbeck, T. R., Devesa, S. S., Chang, B.-L., Bunker, C. H., Cheng, I., Cooney, K., Zeigler-Johnson, C. M. (2013). Global patterns of prostate cancer incidence, aggressiveness, and mortality in men of African descent. Hindawi, 560857. https://doi.org/10.1155/2013/560857

[24] Akigbe, A. \& Akigbe, K. (2012). Effects of health belief and cancer fatalism on the practice of breast cancer screening among Nigerian women: INTECH open science/open mind. Accessed on 23/01/2020 from: $\mathrm{http}: / / \mathrm{www}$.intechopen.com/books/mammography-recentadvantages/effects-of-health-belief-and-cancer-fatalism-onthe-practice-of-breast-cancer-screening-among-nigeria

[25] Agbugui J. O., Obarisiagbon E. O., Nwajei C. O, (2013). Awareness and knowledge of prostate cancer among men in Benin City, Nigeria. Journal of Medicine and Biomedical Research, 12(2), https://www.ajol.info/index.php/jmbr/article/view/104621

[26] Oranusi, C. K., Mbieri, U. T., Oranusi, I. O., \& Nwofor, A. M. E. (2012). Prostate cancer awareness and screening among male public servants in Anambra State, Nigeria. African Journal of Urology, 18(2), 72-74. https://doi.org/10.1016/j.afju.2012.04.016

[27] Hevey, D., Pertl, M., Thomas, K., Maher, L., Chuinneagáin, S. N., \& Craig, A. (2009). The relationship between prostate cancer knowledge and beliefs and intentions to attend PSA screening among at-risk men. Patient Education and
Counselling, 74(2),

https://doi.org/10.1016/j.pec.2008.08.013

[28] International Network for Cancer Treatment and Research. (2013). Building capacity for cancer prevention, treatment and research: cancer control. 10 (11): 167-176. Retrieved on Accessed on 26/01/2020 from http://cancercontrol.info/wpcontent/uploads/2014/08/cc2013_167-176-INCTRsection_2012.pdf

[29] Elamurugan, S., Rajendran, P. \& Thangamani S. (2016). Prostate cancer screening: Awareness, attitude, and practice of Indian women. Trop J Med Res; 19:42-6

[30] Liu, Y., Liu, Y., Yuan, B., Yuan, B., Yin, L., Peng, Y., Yu, X., Zhou, W., Gong, Z., Liu, J., He, L. \& Li, X. (2017). FOXM1 promotes the progression of prostate cancer by regulating PSA gene transcription. Oncotarget.; 8(10):17027 - 17037. https://doi:10.18632/oncotarget.15224

[31] Sothy, T. \& Oh J. K. (2018). Knowledge, attitudes, and practices toward prostate cancer prevention among men in Kampong Speu Province, Cambodia. BMC Cancer; 18(1):294 https://doi.org/10.1186/s12885-018-4198-8

[32] Chan, E. C. Y., McFall, S. L., Byrd, T. L., Mullen, P. D., Volk, R. J., Ureda, J., Kay Bartholomew, L. (2011). A communitybased intervention to promote informed decision making for prostate cancer screening among Hispanic American men changed knowledge and role preferences: a cluster RCT. Patient Education and Counselling, 84(2), 44-51. https://doi.org/10.1016/j.pec.2010.07.033

[33] Allen, J. D., Kennedy, M., Wilson-Glover, A. \& Gilligan, T. D. (2007). African-American men's perceptions about prostate cancer: implications for designing educational interventions. Social Science \& Medicine, 64(11), 2189-2200. https://doi.org/10.1016/j.socscimed.2007.01.007

[34] Watson, E., Hewitson, P., Brett, J., Bukach, C., Evans, R., Edwards, A., Elwyn, G., Cargill, G. \& Austoker, J. (2006). Informed decision making and prostate-specific antigen (PSA) testing for prostate cancer: A randomized controlled trial exploring the impact of a brief patient decision aid on men's knowledge, attitudes and intention to be tested. Patient Education and Counseling, 63 367-379. https://doi.org/10.1016/j.pec.2006.05.005

[35] Cancer Association of South Africa [CANSA], (2013). https://cansa.org.za/south-african-cancer-statistics/

[36] Matthew, A. G., Paradiso, C., Currie, K. L., Finelli, A., Hartman, M., Trachtenberg, L., Ritvo, P. (2011). Patient education and counseling examining risk perception among men with a family history of PC. Patient Education and Counseling, 85(2), 251-257.

[37] Rebbeck T. R, Zeigler-Johnson C. M., Heyns C. F., Gueye S. M (2011): Prostate Cancer Screening, Detection and Treatment Practices, Among Sub-Saharan African Urologists. African Journal of Urology 17(3). 85-91 https://doi.org/10.1007/s12301-011-0016-0 